\title{
PENGETAHUAN IBU HAMIL TENTANG BAHAYA MEROKOK TERHADAP KEHAMILAN DAN JANIN
}

\author{
Melva Manurung ${ }^{1}$, Rina Manalu ${ }^{2}$, Pretty Situmorang ${ }^{3}$ \\ ${ }^{1,2}$ Program Studi D3 Keperawatan STIKes Arjuna \\ ${ }^{3}$ Mahasiswa Program Studi D3 Keperawatan STIKes Arjuna \\ Email:melva_manroe84@yahoo.com
}

\begin{abstract}
Smoking during pregnancy can endanger pregnancy and the fetus, especially the health of pregnant women and fetal development in the womb. One of the complications of pregnancy that causes fetal death is due to oxygenation disorders. In Indonesia, more than half of households have at least one smoker, and almost all smokers' smokes at home. The cause of neonatal death is fetal death in utero, asphyxia or respiratory problems due to smoking and premature. This study aims to determine the knowledge of pregnant women about the dangers of smoking to pregnancy and the fetus in Gasaribu Village, Laguboti, Toba Samosir Regency. This research was conducted in SeptemberOctober 2019 using adescriptive research design. The number of samples was in this study were 40 pregnant women. Sampling is done by using saturated sampling. The results showed that good knowledge of 16 people (40\%) was enough 22 people (55\%) and less 2 people (5\%). The results of this study are expected to be used as additional material in adding knowledge and information to increase real health education (real) to the public about the dangers of smoking to pregnancy and the fetus.
\end{abstract}

Keywords: knowledge, danger of cigarettes, pregnancy, fetus

\section{PENDAHULUAN}

Pembangunan kesehatan adalah tercapainya kemampuan hidup sehat bagi setiap penduduk atau individu agar dapat mewujudkan derajat kesehatan masyarakat yang optimal. Salah satu tantangan pembangunan Indonesia di bidang kesehatan adalah masih tingginya kematian neonatal.

Salah satu target yang telah ditentukan dalam Millennium Development Goals (MDGs, 2015) pada rencana kelima yaitu mewujudkan akses kesehatan reproduksi bagi semua perempuan. Dimana target yang akan dicapai dari tahun 1990 sampai tahun
2015 adalah mengurangi sampai 3/4 resiko jumlah kematian ibu dan kematian anak (Kementerian Kesehatan RI, 2013). AKI (Angka Kematian Ibu) merupakan salah satu indikator yang peka terhadap kualitas dan aksesibilitas fasilitas pelayanan kesehatan. Berdasarkan survei sepanjang tahun 2014 data menunjukkan angka kematian ibu di Indonesia mencapai 5.048, lanjut pada tahun 2015 berkurang menjadi 897 kasus dan data terakhir di tahun 2016 ada 4.834 (Kemenkes RI, 2017).

Menurut data WHO (Word Health Organization), angka kematian janin di dunia di perkirakan sekitar sekitar 3,82- 
22.14 juta jiwa. Kematian janin termasuk dalam masalah perinatal dan merupakan indikator kesehatan yang saat ini sangat sensitif karena berhubungan dengan kesehatan ibu dan anak. Angka kematian perinatal menyumbang sekitar $77 \%$ dari kematian neonatal, dimana kematian perinatal menyumbang $58 \%$ dari total kematian bayi (WHO, 2016).

Indonesia diantara negara ASEAN merupakan negara dengan angka kematian perinatal tertinggi, yang berarti kemampuan untuk memberikan pelayanan kesehatan masih memerlukan perbaikan yang bersifat menyeluruh dan lebih bermutu. Dengan perkiraan persalinan di Indonesia setiap tahun yang sekitar 5.000 .000 jiwa dapat dijabarkan bahwa kematian bayi terjadi setiap 25-26 menit sekali. Berdasarkan Survey Demografi dan Kesehatan Indonesia Angka Kematian Neonatal 19/1000 kelahiran hidup (Kemenkes RI, 2015), sedangkan penyebab kematian neonatal secara umum, yaitu kematian janin dalam rahim $(31,3 \%)$, aspiksia atau gangguan pernafasan $(20,4 \%)$ akibat merokok dan premature $(18,7 \%)$ (Kemenkes RI, 2013).

Menurut data World Health Organitation (WHO, 2017) diperkirakan $45 \%$ wanita yang merokok, dan $27 \%$ wanita hamil yang merokok, sedangkan dari Amerika Serikat sebanyak 23,5\% ibu hamil yang merokok, dan 20\% ibu hamil yang berhenti merokok selama kehamilan, pada ibu hamil yang merokok dapat menimbulkan komplikasi kehamilan. Salah satu komplikasi kehamilan yang menyebabkan kematian janin disebabkan karena adanya gangguan oksigenasi. Lebih separuh (57\%) rumah tangga di Indonesia, mempunyai sedikitnya satu orang perokok, dan hampir semua perokok $(91,8 \%)$ merokok di rumah. Kelangsungan suatu kehamilan sangat bergantung pada keadaan dan kesehatan ibu, plasenta dan keadaan janin. Pengetahuan ibu adalah bagian paling mendasari bagaimana tindakan ibu selama kehamilan dan kelangsungan hidup bayi yang dilahirkan (Kemenkes RI, 2018).

Merokok adalah bentuk utama penggunaan tembakau. Secara nasional, prevalensi merokok adalah sebesar $29 \%$. Provinsi dengan prevalensi merokok tertinggi di Indonesia adalah Jawa Barat $32,7 \%$. Sedangkan prevalensi merokok terendah adalah Provinsi Papua 21,9\%. Terdapat 13 provinsi dari 33 provinsi yang mempunyai prevalensi merokok lebih dari rata-rata nasional (Kemenkes RI, 2018).

Persentase merokok pada penduduk umur $\geq 15$ tahun di provinsi Sumatera Utara pada tahun 2018 terdapat 31,1\% (BPS, 2015). Menurut penelitian Karini 
dan Padmawati (2018) menyatakan penyebab perilaku merokok pada wanita adalah karena meniru teman, pengaruh ibu yang juga perokok, dan keinginan mencium aroma asap rokok saat hamil. Perilaku merokok wanita terus berlanjut karena mereka merasa puas bila merokok setelah makan. Selain itu, wanita perokok mendapat dukungan dari suami. Penelitian juga menemukan belum pernah dilakukan edukasi kesehatan tentang bahaya merokok terhadap kesehatan untuk para wanita.

Semakin lama ibu hamil bersama perokok aktif di dalam rumah dengan rata-rata ibu terpapar asap rokok $>7$ jam setiap harinya, maka risiko melahirkan bayi dengan berat badan lahir rendah semakin tinggi. Zat berbahaya dari rokok yang terisap oleh ibu hamil akan terbawa ke aliran darah ibu sehingga menyebabkan penerimaan oksigen bayi maupun plasenta berkurang, yang berarti berkurang juga penerimaan nutrisi untuk bayi. Hal ini mengakibatkan kematian sel karena kekurangan oksigen. Hipoksia pada janin dan menurunnya aliran darah umbilikal dapat menyebabkan gangguan pertumbuhan pada janin sehingga menyebabkan BBLR (Hanifah, 2017).

Penelitian Paunno, Emilia, dan Wahab (2016) menyatakan ada hubungan yang bermakna antara ibu hamil perokok pasif dengan kejadian lahir mati. Faktor-faktor risiko lain yang mempengaruhi kejadian lahir mati adalah: Kualitas antenatal care, ibu hamil anemia dan pendidikan. Saat analisis strativikasi, ibu tidak anemia mempunyai hubungan bermakna dengan lahir mati. Umur, paritas dan pendidikan bukan merupakan faktor risiko lahir mati di Kota Ambon.

Faktor pengetahuan suami yang kurang mengetahui tentang bahaya rokok yaitu dimana suami yang merokok didalam rumah saat bersama istri dan anak-anaknya sehingga dampak buruk pada ibu hamil yang terpapar asap rokok dapat membahayakan kehamilan dan janin.

Hasil penelitian Astuti, Susanti, dan Elista (2016) menunjukkan Ibu hamil yang terpapar asap rokok suami yang merokok di dalam rumah berdasarkan usia kehamilan paling besar didapatkan pada usia kehamilan 13-28 minggu. Paparan jumlah batang rokok per hari sebanyak >10 batang paling besar didapatkan pada usia kehamilan 13-28 minggu. Ibu hamil yang terpapar asap rokok dalam setiap hari selama hamil selain di rumah paling besar didapatkan pada usia kehamilan 13-28 minggu.

Berdasarkan uraian dan fenomena diatas maka penulis tertarik melakukan penelitian yang berjudul pengetahuan ibu hamil tentang bahaya rokok terhadap kehamilan dan janin di Desa Gasaribu 
Kecamatan Laguboti Kabupaten Toba Samosir tahun 2019.

\section{METODE}

Desain penelitian ini adalah deskriptif dengan menggunakan rancangan cross sectional yang bertujuan untuk mengidentifikasi pengetahuan ibu hamil tentang bahaya rokok terhadap kehamilan dan janin di Desa Gasaribu Kecamatan Laguboti Kabupaten Toba Samosir tahun 2019. Jumlah sampel sebanyak 40 orang dan menggunakan teknik Sampling jenuh. Pengambilan data dilakukan pada bulan September-Oktober 2019 di Desa Gasaribu Kecamatan Laguboti.

Analisa data menggunakan univariat yang ditampilkan pada data distribusi frekuensi dan persentase.

\section{HASIL DAN PEMBAHASAN}

Karakteristik Responden Tabel 1. Distribusi Frekuensi Karakteristik Ibu Hamil

\begin{tabular}{clrr}
\hline No. & Karakteristik Frekuensi & \% \\
\hline 1 & Umur & & \\
& $<20$ Tahun & 19 & 47,5 \\
& $20-35$ & 21 & 52,5 \\
& Tahun & & \\
\hline 2 & Pendidikan & & \\
& SD & 2 & 5,0 \\
& SMP & 6 & 15,0 \\
& SMA & 25 & 62,5 \\
& Diploma & 1 & 2,5 \\
& Sarjana & 6 & 15,0 \\
\hline 3 & Pekerjaan & & \\
& IRT & 24 & 60,0 \\
& Wiraswasta & 8 & 20,0 \\
& PNS & 8 & 20,0 \\
\hline & & &
\end{tabular}

Berdasarkan tabel diatas diketahui bahwa usia responden terbanyak berada pada rentang 20-35 tahun yaitu sebanyak 21 responden $(52,5 \%)$, pendidikan responden terbanyak adalah sekolah menengah atas (SMA) sebanyak 25 responden $(62,5 \%)$ dan pekerjaan responden yang terbanyak yaitu ibu rumah tangga (IRT) sebanyak 24 responden $(60,0 \%)$.

Pengetahuan Ibu Hamil Tentang Bahaya Rokok Terhadap Kehamilan dan Janin

Tabel 2. Distribusi $\quad$ Frekuensi Pengetahuan Ibu Hamil Tentang Bahaya Rokok Terhadap Kehamilan dan Janin

\begin{tabular}{clrr}
\hline No & Pengetahuan & Frekuensi & \multicolumn{1}{c}{$\%$} \\
\hline 1 & Kurang & 2 & 5,0 \\
2 & Cukup & 22 & 55,0 \\
3 & Baik & 16 & 40 \\
& & 40 & 100 \\
\hline
\end{tabular}

Berdasarkan tabel diatas dapat diketahui bahwa pengetahuan responden tentang bahaya rokok terhadap kehamilan dan janin lebih banyak adalah berpengetahuan cukup yaitu sebanyak 22 responden $(55,0 \%)$, dan terendah adalah berpengetahuan kurang sebanyak 2 responden $(5.0 \%)$.

\section{Pembahasan}

Pengetahuan merupakan domain yang penting dalam mengetahui pengetahuan untuk menentukan tindakan seseorang. Pengetahuan merupakan hasil dari tahu yang terjadi setelah orang melakukan penginderaan 
terhadap suatu objek tertentu. Pengetahuan merupakan suatu domain yang sangat penting untuk terbentuknya suatu tindakan seseorang. Suatu penelitian mengatakan bahwa perilaku yang didasari oleh pengetahuan akan mampu bertahan lama dari pada yang tidak didasari oleh pengetahuan. Pengetahuan dapat dipengaruhi pendidikan, pekerjaan dan sumber informasi (Notoatmodjo, 2012). Hasil penelitian menunjukkan pengetahuan ibu hamil tentang bahaya rokok terhadap kehamilan dan janin di Desa Gasaribu Kecamatan Laguboti Kabupaten Toba Samosir adalah sebagian besar berpengetahuan cukup yaitu sebanyak 22 orang (55\%), sedangkan ibu hamil yang berpengetahuan baik yaitu sebanyak 16 orang (40\%) dan ibu hamil yang berpengetahuan kurang yaitu sebanyak 2 orang (5\%).

Pengetahuan adalah hasil tahu yang terjadi setelah individu melakukan penginderaan terhadap objek tertentu dan sebagian besar pengetahuan manusia diperoleh dari mata dan telinga.Pengetahuan juga dapat diperoleh dari pengalaman langsung maupun tidak langsung (Notoatmodjo, 2012).

Setelah diketahui bahwa tingkat pengetahuan ibu hamil tentang bahaya rokok terhadap kehamilan dan janin adalah cukup dimana pengetahuan ibu hamil tentang bahaya rokok sangatlah berguna bagi peningkatan kesehatan kehamilan dan janin, dalam pengetahuan ini, peneliti mendapatkan bahwa pengetahuan ibu hamil tentang bahaya rokok yang terbilang cukup dikarenakan ibu hamil kurang menyadari bahwa pentingnya kewaspadaan tentang bahaya rokok terhadap kehamilan dan janin

Dalam penelitian bahwa pengetahuan ibu hamil adalah cukup dimana peneliti membuktikan bahwa pengetahuan dipengaruhi oleh tingkat pendidikan responden, karena dari data krateristik pendidikan responden sebagaian besar tingkat pendidikan responden adalah SMA sebanyak 25 orang $(62,5 \%)$ dan berpendidikan paling terendah yaitu pendidikan SD sebanyak 2 orang $(5.0 \%)$.

Sesuai pernyataan Notoatmodjo (2012) bahwa dengan meningkatnya pendidikan seseorang maka tingkat pengetahuannya juga meningkat. Hal ini dapat terjadi karena dengan meingkatnya pendidikan seseorang maka lebih banyak informasi dan berusaha untuk mencari hal baru yang belum mereka ketahui sesuai dengan tingkat pendidikannya, maka dari itu semakin tinggi tingkat pendidikan seseorang maka semakin tinggi pengetahuan yang dimiliki.

Pengetahuan sangat mempengaruhi dengan adanya faktor eksternal dan 
internal dimana dalam pengetahuan memiliki cara berfikir secara domain kognitif sehingga faktor pengetahuan eksternal dan internal sangat dibutuhkan dalam memperoleh hasil pengetahuan yang baik, cara berfikir manusia sangat unik dalam berfikir manusia mampu memiliki pengetahuan dan wawasan yang lebih baik. Dimana faktor pengetahuan eksternal juga berpengaruh terhadap pengetahuan ibu hamil tentang bahaya rokok terhadap kehamilan dan janin, faktor eksternal yang berpengaruh terhadap pengatahuan adalah hasil data dari karakteristik pekerjaan dimana pekerjaan responden juga akan mempengaruhi pengetahuan dalam penelitian ini karekteristik pekerjaan responden yang paling banyak adalah ibu rumah tangga (IRT) sebanyak 24 orang $(60 \%)$. Faktor eksternal yaitu pekerjaan ibu berpengaruh terhadap pengetahuan dimana dalam pekerjaan seseorang akan meningkatkan wawasan dalam pengetahuan.

Hasil penelitian Hutabarat, Rochadi, dan Aulia (2019) menunjukkan bahwa pendidikan, pengetahuan, dan persepsi tentang peringatan bahaya merokok di iklan memiliki pengaruh. tentang perubahan sikap perokok aktif, sedangkan usia, pekerjaan, dan kebiasaan merokok tidak variabel yang memiliki pengaruh paling dominan adalah variabel pendidikan. Perokok aktif yang memiliki pendidikan tinggi, pengetahuan yang baik, dan memiliki persepsi yang baik tentang peringatan akan bahaya merokok pada bungkus rokok dalam iklan memiliki peluang 57\% untuk mengubah sikap mereka yang mengindikasikan bahwa sangat sulit untuk mengubah sikap perokok terhadap merokok karena sudah menjadi kebiasaan.

Pengetahuan sangat berperan penting dalam mengetahui pengetahuan responden dalam bahaya rokok terhadap kehamilan dan janin. Pada ibu hamil yang memiliki pengetahuan cukup tentang bahaya rokok terhadap kehamilan dan janin diharapkan akan tumbuh perilaku yang sehat dalam menghadapi bahaya rokok terhadap kehamilan dan janin. Pada perokok aktif sudahlah sangat jelas tentang bahaya terhadap kehamilan dan janin dan perokok pasif pun sangat bahaya seperti perokok aktif yang dapat membahaya kehamilan dan janin.Pengetahuan sangat berperan dalam kehidupan manusia dalam memelihara kesehatannya khususnya pada ibu hamil tentang bahaya rokok terhadap kehamilan dan janinnya.

Paparan asap rokok dari suami maupun anggota keluarga lain terbukti meningkatkan risiko kejadian BBLR. Faktor risiko lainnya yang juga dijumpai meningkatkan risiko kejadian BBLR 
adalah umur ibu, status pekerjaan, status gizi ibu, jarak kehamilan dan pendapatan keluarga (Lestari, Putra, \& Karmaya, 2015).

Hasil penelitian Narita, Kusumawati, dan Wijayanti (2016) menunjukkan bahwa ada hubungan antara usia, paparan asap rokok pada ibu dan tidak ada hubungan antara pekerjaan dengan kejadian BBLR di Kecamatan Banyudono Kabupaten Boyolali. Hubungan faktor risiko usia dan paparan asap rokok pada ibu dengan kejadian BBLR tidak dirancukan oleh status gizi, status anemia, dan kunjungan ANC

Penelitian Muntoha, Suhartono, \& Wahyuningsih (2013) menunjukkan kejadian KPD disebabkan oleh paparan asap rokok sehingga ibu hamil yang terpapar asap rokok memiliki peluang 23 kali lebih tinggi untuk mengalami KPD. Penelitian (Kristina \& Yunamawan 2018) menunjukkan ada hubungan antara nutrisi sedang, usia ibu kurang dari 20 tahun atau lebih dari 35 tahun dan terkena paparan asap rokok cukup tinggi dengan terjadinya berat badan lahir rendah di Rumah Sakit Baptis Batu.

\begin{tabular}{lrr}
\multicolumn{1}{c}{ Peneliti } & berasumsi & bahwa \\
pengetahuan & responden & juga \\
dipengaruhi oleh pendidikan karena \\
dalam penelitian mayoritas responden \\
berlatar belakang pendidikan adalah \\
SMA/sederajat.
\end{tabular}

Hasil penelitian yang telah dilakukan bahwa pengetahuan ibu hamil tentang bahaya rokok terhadap kehamilan dan janin berpengetahuan cukup dimana pengetahuan sangat berperan aktif dalam mengetahuai bahaya rokok terhadap kehamilan dan janin, dan pengetahuan juga harus dibarengi oleh pendidikan ibu hamil dari pendidikan ibu hamil dapat mempengaruhi hasil pengetahuan yang akan lebih baik dalam mendukung kesehatan kehamilan dan janinnya terhadap bahaya rokok. Pengetahuan ibu hamil juga dapat mengantisipasi dirinya dari penyakit khususnya pada kehamilan dan janin terhadap rokok agar tidak terjadi sesuatu yang dapat membahayakan kehamilan baik bagi dirinya dan janinnya.

\section{DAFTAR PUSTAKA}

Astuti, S., Susanti, A. I., \& Elista, R. (2016). Gambaran paparan asap rokok pada ibu hamil berdasarkan usia kehamilan di desa Cintamulya Kecamatan Jatinangor Kabupaten Sumedang. Jurnal Sistem Kesehatan. https://doi.org/10.24198/jsk.v2i1.104 13

BPS. (2015). Statistik Indonesia 2015. In Statistik Indonesia. https://doi.org/10.1017/CBO9781107 415324.004

Hanifah, H. (2017). Pengaruh Paparan Asap Rokok Lingkungan pada Ibu Hamil Terhadap kejadian bayi berat lahir rendah. Skripsi.

Hutabarat, E. N. N., Rochadi, R. K., \& Aulia, D. (2019). Pengaruh karakteristik dan persepsi individu tentang peringatan bahaya merokok 
pada bungkus rokok terhadap perubahan sikap perokok aktif di lingkungan XXVII Kelurahan Pekan Labuhan Kecamatan Medan Labuhan. Jurnal Muara Sains, Teknologi, Kedokteran Dan Ilmu Kesehatan.

https://doi.org/10.24912/jmstkik.v3i1 .1539

Karini, T. A., \& Padmawati, R. S. (2018). Fenomena sosial unik pada perokok wanita di kabupaten Lebong Bengkulu Indonesia. Berita Kedokteran Masyarakat, 34(1). Retrieved from https://media.neliti.com/media/public ations/237887-none-034f3c75.pdf

Kementerian Kesehatan RI. (2013). Riskesdas Tahun 2013. Jakarta: Badan Penelitian Dan Pengembangan Kesehatan Departemen Kesehatan Republik Indonesia. https://doi.org/10.1007/s13398-0140173-7.2

Kementerian Kesehatan RI. (2017). Survey Demografi dan Kesehatan Indonesia. In Survei Demografi dan Kesehatan Indonesia 2017. https://doi.org/0910383107 [pii]ไr10.1073/pnas.0910383107

Kementerian Kesehatan RI. (2015). Angka Kematian Ibu. Rubrik Kesehatan.

Kementerian Kesehatan RI. (2018). Situasi Umum Konsumsi Tembakau. Infodatin.

Kristina, D., \& Yunamawan, D. (2018). Hubungan nutrisi, usia ibu waktu hamil dan asap rokok dengan terjadinya berat badan lahir rendah di Rumah Sakit Baptis Batu. Biomed Science.

Lestari, K. S. D., Putra, I. W. G. A. E., \& Karmaya, I. N. M. (2015). Paparan asap rokok pada ibu hamil di rumah tangga terhadap risiko peningkatan kejadian bayi berat lahir rendah di Kabupaten Gianyar. Public Health and Preventive Medicine Archive. https://doi.org/10.15562/phpma.v3i1. 94
Muntoha, Suhartono, \& Wahyuningsih, N, E. (2013). Hubungan antara riwayat paparan asap rokok dengan kejadian ketuban pecah dini pada ibu hamil di RSUD Dr. H. Soewondo Kendal. (2013). Jurnal Kesehatan Lingkungan Indonesia. https://doi.org/10.14710/jkli.12.1.8893

Narita, A., Kusumawati, Y., \& Wijayanti, A. C. (2016). Faktor risiko usia, pekerjaan dan paparan asap rokok pada ibu dengan kejadian berat bayi lahir rendah di Kecamatan Banyudono Kabupaten Boyolali.

Notoatmodjo, S. (2012). Promosi Kesehatan dan Perilaku Kesehatan. In Journal of Chemical Information and Modeling. https://doi.org/10.1017/CBO9781107 415324.004

Paunno, M., Emilia, O., \& Wahab, A. (2016). Pengaruh ibu hamil perokok pasif terhadap kejadian lahir mati di Kota Ambon. Jurnal Kesehatan Reproduksi. https://doi.org/10.22146/jkr.12647

WHO. (2016). WHO | New guidelines on antenatal care for a positive pregnancy experience.

WHO. (2017). 2017 Health SDG Profile: Indonesia. World Health Organization. 